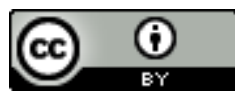

\title{
GAMIFICAÇÃO COMO UM PROCESSO DE MUDANÇA NO ESTILO DE ENSINO APRENDIZAGEM NO ENSINO SUPERIOR: UM RELATO DE EXPERIÊNCIA
}

\author{
GAMING AS A PROCESS OF CHANGE IN TEACHING STUDY LEARNING IN HIGHER \\ EDUCATION: AN ACCOUNT OF EXPERIENCE
}
GAMIFICACIÓN COMO UN PROCEDIMIENTO DE CAMBIO EN EL ESTILO DE ENSEÑANZA APRENDIZAJE EN LA ENSEÑANZA SUPERIOR: UN RELATO DE EXPERIENCIA

\section{Thaís Branquinho Oliveira Fragelli ${ }^{\mathrm{i}}$}

\begin{abstract}
RESUMO: Debates atuais têm enfatizado a mudança do comportamento do discente em relação ao seu processo de aprendizagem. Observa-se que o estudante atual tem a necessidade de informações em um curto espaço de tempo e, por muitas vezes, se dispersam com facilidade em contextos de aulas exclusivamente tradicionais e expositivas. Considerando esse aspecto, o presente trabalho tem o objetivo de relatar a experiência com o uso da gamificação em uma turma de $4^{\circ}$ e outra de $7^{\circ}$ semestres da grade curricular obrigatória e, em uma turma de disciplina optativa do curso de graduação em Fisioterapia, participando assim 90 alunos, na tentativa de aproximar o aluno do conteúdo, motivar o aprendizado e tornar o ambiente da sala de aula mais próximo e mais atrativo ao estudante. Ao final das aulas foram aplicados questionários para que o estudante pudesse avaliar a experiência. A avaliação realizada pelos estudantes relacionou-se a relatos de maior motivação, e o despertar do interesse para um aprofundamento maior do conteúdo.
\end{abstract}

PALAVRAS-CHAVE: Aprendizagem ativa. Ensino superior. Gamificação. Técnicas de ensino-aprendizagem

ABSTRACT: Current debates have emphasized the change in student behavior in relation to their learning process. It is observed that the current student has the need for information in a short space of time, and often disperses easily in contexts of exclusively traditional and expository classes. Considering this aspect, the present work aims to report the experience with the use of gamification in the 4th and 7th semesters of the compulsory curriculum and in an optional course group of the undergraduate course in Physiotherapy, thus participating 90 students, in an attempt to bring the student closer to the content, motivate the learning and make the classroom environment closer and more attractive to the student. At the end of the classes, questionnaires were applied so that the student could evaluate the experience. The students' evaluation was related to reports of greater motivation, and the awakening of the interest for a greater deepening of the content.

KEYWORDS: Active learning. Higher education. Gamification. Teaching-learning techniques.

RESUMEN: Los debates actuales han enfatizado el cambio del comportamiento discente en relación con su proceso de aprendizaje. Se observa que el estudiante actual tiene la necesidad de informaciones en un corto espacio de tiempo y, a menudo, se dispersan con facilidad en contextos de clases exclusivamente tradicionales y expositivas. En este aspecto, el presente trabajo tiene el objetivo de relatar la experiencia con el uso de la gamificación en clase de $4^{\circ}$ y de $7^{\circ}$ semestres de la cuadrícula curricular obligatoria y, en una clase de disciplina optativa del curso de graduación en Fisioterapia, participando así 90 alumnos, en el intento de aproximar al alumno del contenido, motivar el aprendizaje y hacer el ambiente del aula más cercano y más atractivo al estudiante. Al final de las clases se aplicaron cuestionarios para que el estudiante pudiera evaluar la experiencia. La evaluación realizada por los estudiantes se relacionó con relatos de mayor motivación, y el despertar del interés para una profundización mayor del contenido.

PALABRAS CLAVE: Aprendizaje activo. Enseñanza superior. Gamificación. Técnicas de enseñanza-aprendizaje.

Submetido em: 08/09/2017 - Aceito em: 10/10/2017 - Publicado em: 28/10/2017.

\begin{tabular}{l|l|l|l|l|l} 
(C) Rev. Inter. Educ. Sup. & Campinas, SP & v.4 & n.1 & p.221-233 & jan./abr. 2017 \\
\hline
\end{tabular}




\section{INTRODUÇÃ̃}

Atualmente as universidades têm encontrado cada vez mais alunos com maior facilidade em se tornar desinteressados pelo conteúdo e dispersos em sala de aula, principalmente, quando as metodologias de ensino e de aprendizagem utilizadas pelo professor são exclusivamente passivas (FARDO, 2013).

As metodologias conservadoras têm pautado historicamente a formação dos profissionais de saúde, traduzindo em um processo de ensino-aprendizagem restrito à reprodução de conhecimento e à transmissão de conteúdo por parte do docente combinado a passividade acrítica e arreflexiva por parte do discente (MITRE et al., 2008).

E nesse ciclo de arreflexão e de passividade, o processo de ensino-aprendizagem acaba sendo reproduzindo no cotidiano profissional, de maneira a fortalecer um modelo de saúde que já está ultrapassado, onde as relações interpessoais, seja entre profissionais de uma mesma equipe, seja entre profissionais e pacientes, estão cada vez mais deterioradas (ARAÚJO E VIEIRA, 2013).

Para que esse contexto seja revitalizado têm-se defendido que a aprendizagem deva ser voltada para dimensões humanísticas e que possa evocar a afetividade para além da visão restrita da intelectualidade, com empatia e com colaboração, de maneira que a aprendizagem possa se tornar mais sólida e mais duradoura (ROGERS, 1986). Nessa perspectiva, uma consciência indagadora deve ser estimulada para que, por meio de uma curiosidade criativa do discente, surja a autonomia, entremeando a docência e a discência de maneira em que uma não seja objeto da outra e, sim parte de uma mesma identidade (MITRE et al., 2008).

E, como segmento dessa construção entrelaçada emerge a aprendizagem significativa, como estratégia para o docente, que se propõe em não ter apenas um conteúdo potencialmente significativo, mas ser um elemento facilitador na edificação de uma atitude mais favorável e com mais motivação do discente para com a aprendizagem (MITRE et al., 2008).

No que se refere a esses aspectos, várias metodologias têm emergido e levantam discussões acerca da necessidade de que novas estratégias sejam adotadas para que o processo de ensino e de aprendizagem seja redesenhado. Assim, como um caminho interessante surge a gamificação, definida como o uso de elementos de design de jogos em contexto que não seja de jogos (AHMED et al., 2015). É um campo recente que tem despertado o interesse da comunidade acadêmica já que os jogos constituem uma forma de entretenimento bem popular entre indivíduos de todas as idades e, principalmente, dos jovens (ARAÚJO; VIEIRA, 2013). 
A literatura aponta que os jogos incentivam o desempenho ativo dos alunos no processo de aprendizagem apoiando assim, a aprendizagem ativa, a aprendizagem experiencial e a aprendizagem baseada em problemas (MARTÍ-PARREÑO; SEGUÍ-MAS; SEGUÍ-MAS, 2016).

Hamari et al. (2014) realizou uma revisão que identificou estudos com resultados eficazes da gamificação no que se refere ao aumento da motivação, do engajamento e da satisfação dos estudantes nas atividades favorecendo uma melhor qualidade do resultado da aprendizagem. Esse poder motivacional pode ser devido aos mecanismos de incentivo e de envolvimento que compõe os jogos como, por exemplo, uma recompensa, a alegria de jogar e/ou a possibilidade de ganhar (SEIXAS; GOMES; MELO FILHO, 2016).

Assim, entendendo a importância com que os jogos são vistos atualmente é que pensou-se em utilizar mecânicas, estratégias e pensamentos presentes nos games para auxiliar na promoção da aprendizagem. Essa estratégia constitui uma forma de criar um ambiente facilitador da aprendizagem na medida em que se aproxima dessa geração denominada de gamer (FARDO, 2013; ARAÚJO; VIEIRA, 2013).

Com base em tais aspectos, o objetivo do presente trabalho é apresentar uma experiência de utilização da gamificação em ambiente de sala de aula, como uma estratégia para proporcionar uma aprendizagem ativa, significativa e motivadora centrada no aluno, reorientando o processo de ensino-aprendizagem.

\section{DESCRIÇÃO DA EXPERIÊNCIA}

A experiência foi realizada em três disciplinas diferentes, em turmas de semestres distintos do curso de graduação em Fisioterapia, uma turma de $4^{\circ}$, outra de $7^{\circ}$ semestre e uma disciplina optativa com alunos de vários semestres distintos, na Universidade de Brasília. Ao todo participaram 90 alunos. Foram desenvolvidos três games que foram utilizados em sala nos momentos dos conteúdos correspondentes dentro do planejamento da disciplina: 1) Flash card goniométrico, na disciplina Fisioterapia no Processo de Reabilitação: Avaliação; 2) Jogo da fratura, na disciplina Fisioterapia no Processo de Reabilitação: Intervenção e 3) Jogo da anatomia radiológica, na disciplina Prática da Fisioterapia Baseada em Problemas.

Para que fosse possível ter uma visão mais objetiva do que estava sendo observado pela docente no momento das atividades, foi construído um questionário específico para que os discentes pudessem avaliar a aula e a experiência do jogo na sua percepção. Foi solicitado que o discente não se identificasse. Outro objetivo da escala foi verificar a aceitabilidade do jogo pelo discente. Esses games e o contexto em que foram desenvolvidos serão descritos a seguir.

(C) Rev. Inter. Educ. Sup. \begin{tabular}{l|l} 
Campinas, SP & v.4
\end{tabular}

n.1

p.221-233 jan./abr. 2017 


\section{Flash Card Goniométrico}

A avaliação do paciente constitui um processo importante para o estabelecimento da conduta fisioterapêutica, e para isso alguns instrumentos de medida são necessários para que o fisioterapeuta tenha um parâmetro para evolução de sua conduta. A goniometria é uma técnica muito utilizada no contexto do profissional fisioterapeuta como um recurso para avaliação fisioterapêutica e tem a finalidade de mensurar amplitudes articulares. $\mathrm{O}$ conteúdo desse tópico da disciplina a ser aprendido é pouco motivador, pois os alunos devem memorizar angulações articulares e as formas padrão de se realizar a medida. Na prática e na linguagem do aluno é uma matéria que requer muita memorização. Assim, foi criado um jogo com o conteúdo da técnica de goniometria.

Material utilizado. O jogo foi composto por cartas e por goniômetros (instrumento de medida de amplitudes articulares). As cartas tinham três lados: o primeiro constava o movimento articular, o segundo a angulação de amplitude normal referenciada pela literatura e o terceiro como executar a medida.

a) Material utilizado: cartas pré-confeccionadas pelo docente e goniômetros.

b) Mecânica/Dinâmica do jogo. A sala foi dividida em grupos de, no máximo, quatro alunos. Cada grupo recebeu um conjunto de cartas contendo todos os movimentos articulares a serem estudados. Esse conjunto de cartas foi separado e foi distribuído para cada membro do grupo. O primeiro aluno retira uma carta e lê o movimento articular a ser mensurado. Então, ele deve dizer qual o ângulo do movimento. Se houver acerto, o aluno prossegue realizando a mensuração articular sem consulta a nenhum material, conforme pode ser observado na Figura 1. Após as respostas o aluno pode conferir se acertou ou se errou na própria carta que contém também o gabarito. Caso ocorra o acerto de todas as etapas, ele descarta a carta e o próximo participante prossegue. Caso ocorra o erro, o aluno que errou pegaria todas as cartas anteriormente descartadas pelos demais participantes anteriores a ele e, posteriormente, segue o próximo participante. $\mathrm{O}$ jogo termina quando algum dos alunos tiver conseguido descartar todas as cartas de sua mão. 


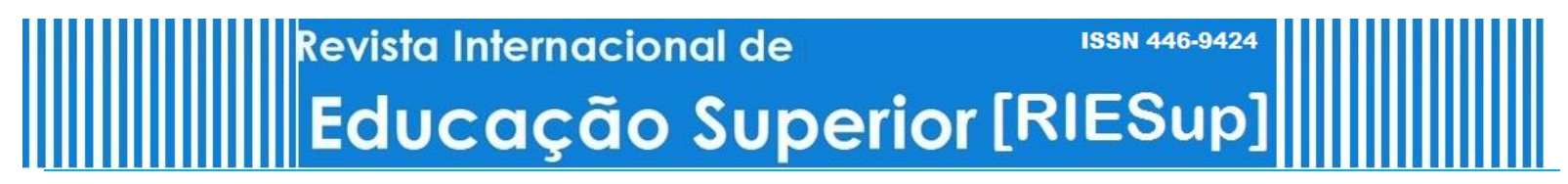

Relato de Experiência

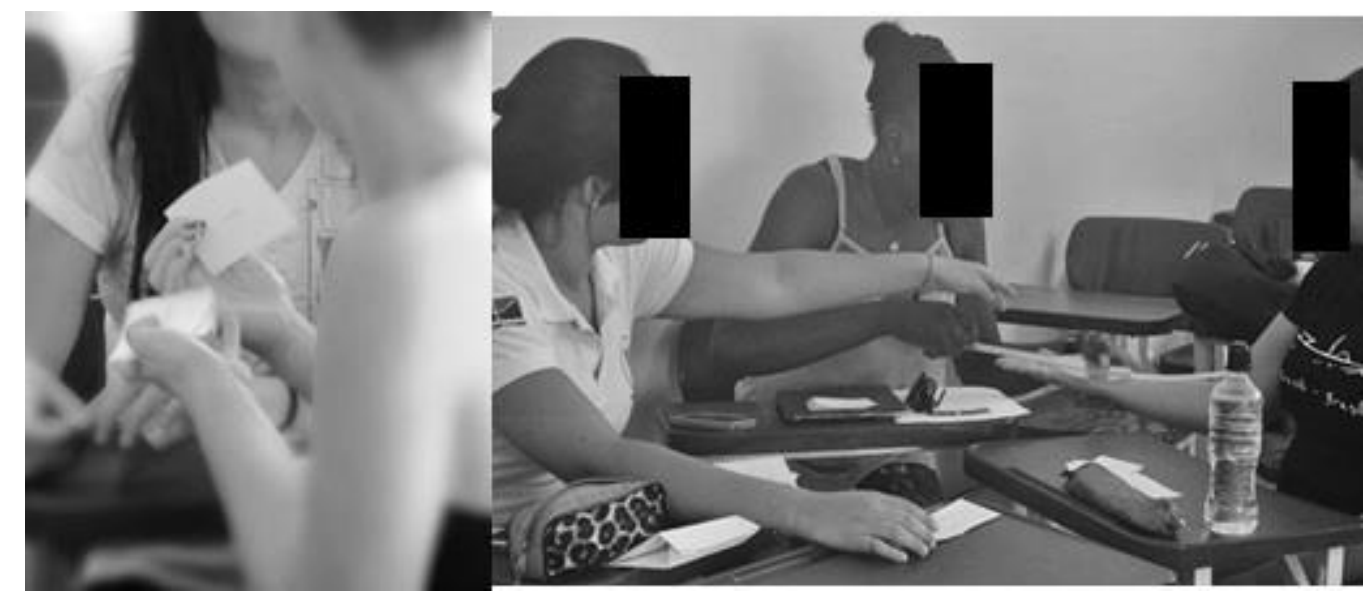

Figura 1. Cartas do Flash Card e momento em que os alunos fazem a goniometria durante o jogo.

Fonte: fotos tiradas em sala de aula pela docente.

\section{Jogo da Fratura}

Dentre as várias patologias recebidas pelo fisioterapeuta em sua prática profissional está a fratura. Assim, o aluno de fisioterapia deve compreender a biomecânica e os mecanismos que as fraturas podem ocorrer pois, esse entendimento se relaciona diretamente com o prognóstico da reabilitação. Assim, como uma forma de entender todo esse processo é que foi idealizado o jogo da fratura.

a) Material utilizado. Para execução do jogo foi utilizado macarrão tipo espaguete, barbantes, pesos e anilhas. O um suporte de arame foi construído pela docente para que os alunos pudessem apoiar os pesos e anilhas conforme visto na Figura 2.

b) Mecânica/Dinâmica do jogo. A turma foi dividida em grupos quatro participantes e, foram distribuídos o macarrão e os pesos bem como as orientações da atividade. Cada membro do grupo deveria opinar sobre qual o peso em que achava que o macarrão poderia "fraturar", e esses palpites seriam anotados. As anilhas foram sendo colocadas nos suporte, aos poucos, sem permitir a torção do macarrão. Assim que o macarrão "fratura" os discentes deveriam verificar quem do grupo mais se aproximou do peso anotado no início do jogo. O jogo pode prosseguir quantas vezes os discentes quiserem. 


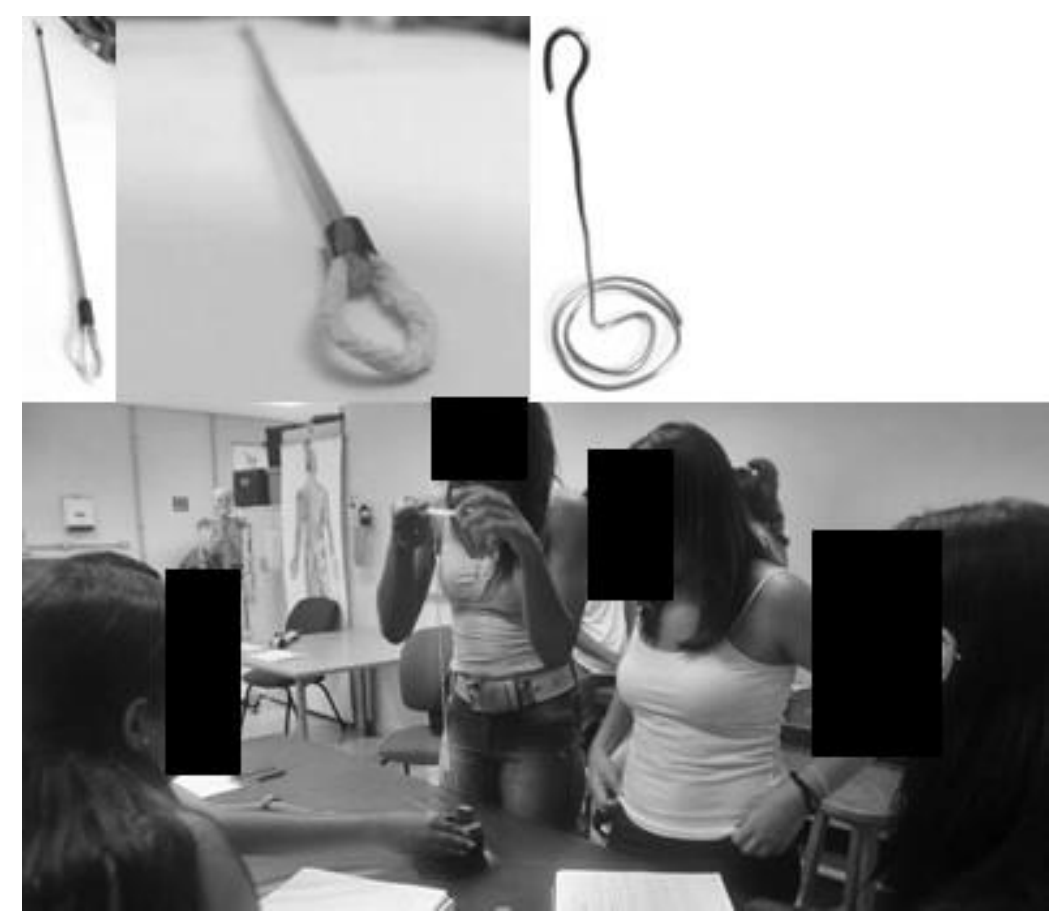

Figura 2. Materiais utilizados para o jogo da Fratura e momento em sala de aula em que os alunos vivenciam a experiência.

Fonte: Fotos tiradas em sala de aula pela docente.

\section{Jogo da Anatomia radiológica}

A anatomia radiológica é um conteúdo importante para avaliação de exames de imagem. Ter a capacidade de distinguir as estruturas em uma radiografia é fundamental para o fisioterapeuta conseguir detectar onde se encontram as disfunções e entender suas causas. Tal conhecimento é necessário pois pode impactar na conduta fisioterapêutica. Assim, a construção do jogo teve como objetivo tornar a compreensão mais palpável para o discente.

a) Material utilizado. Para execução do jogo foi construído pela docente um tabuleiro e as cartas com o conteúdo da matéria, acrescentou-se ainda dados e pinos para identificar cada jogador. As cartas continham imagens radiológicas com sinalizações dos pontos anatômicos a serem identificados, conforme pode ser observado na Figura 3.

b) Mecânica/Dinâmica do jogo. Os alunos foram divididos em grupos de acordo com o número de tabuleiros disponíveis. Um aluno por vez pega uma carta na mesa e joga o dado a primeira vez. O número que estiver constando no dado depois de jogado corresponde ao número do marco anatômico da carta. Nesse momento o discente deve identificar o marco anatômico correspondente. Se houver acerto o aluno pode jogar o dado novamente para "andar" as casas do tabuleiro. Se houver erro, o aluno fica impedido de jogar novamente o 


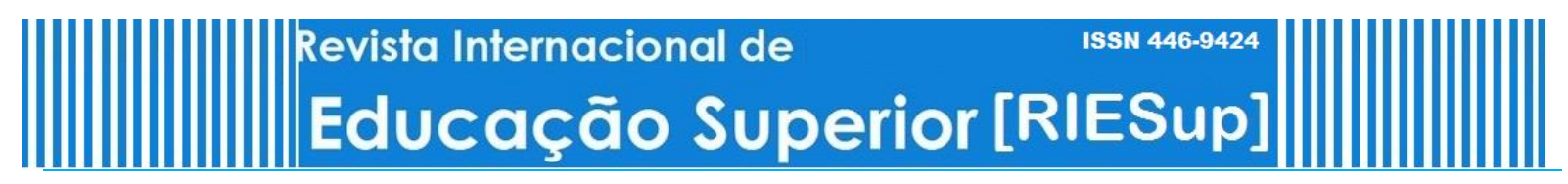
Relato de Experiência

dado passando sua vez para outro participante prosseguir o jogo. O jogo finaliza quanto algum dos participantes chegar ao final do tabuleiro.
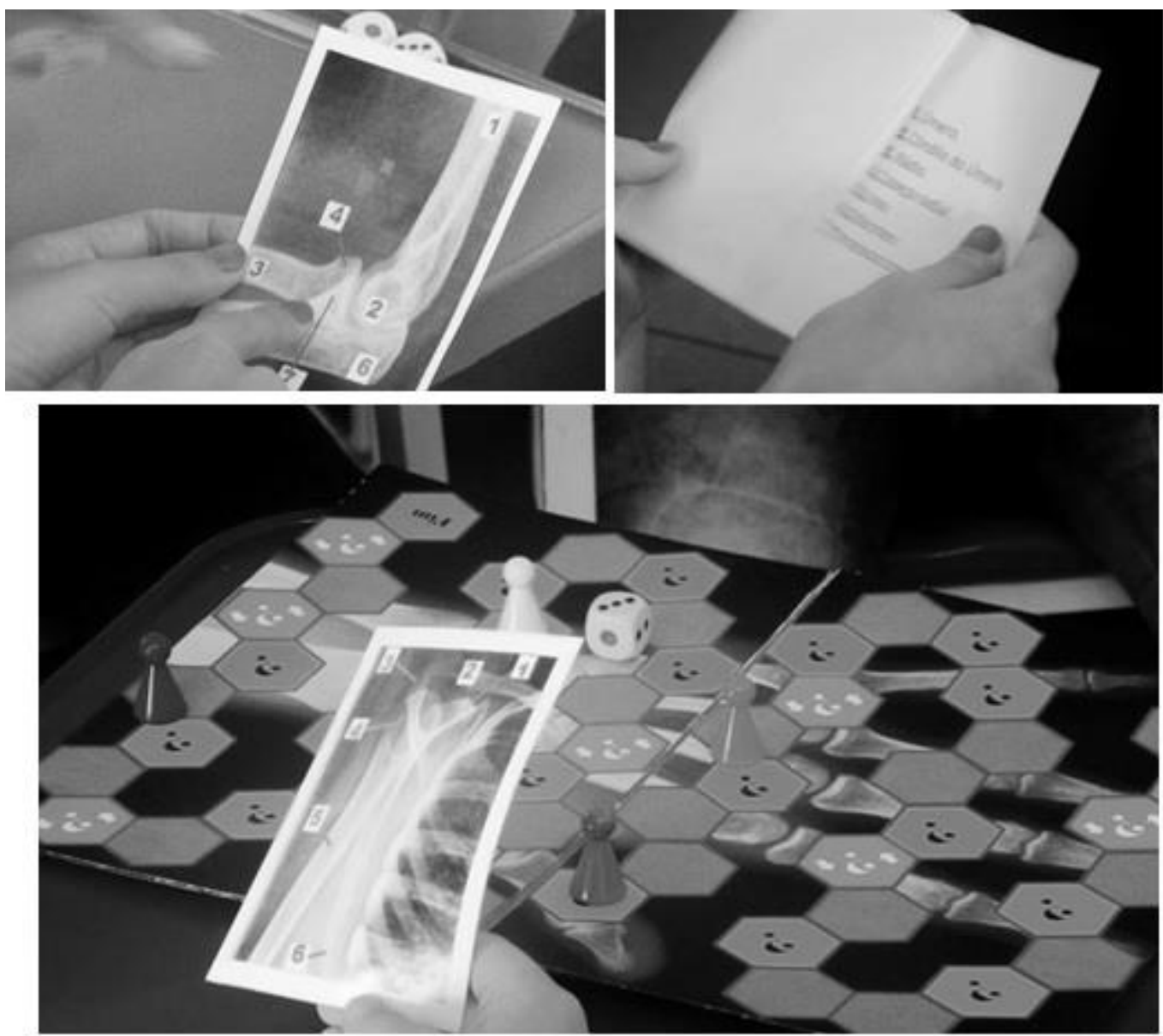

Figura 3. Cartas do jogo em que tem a imagem radiológica com os pontos anatômicos a serem indicados e no interior o gabarito. Abaixo o tabuleiro.

Fonte: Fotos tirada pela docente em sala de aula.

\section{RESULTADOS}

A princípio, quando a atividade foi proposta houve uma atitude de estranhamento por parte dos alunos. À medida que a mecânica/dinâmica dos jogos foi sendo explicada, os alunos foram se mostrando mais receptivos e, todos aceitaram participar. No decorrer da atividade, foi nítida a demonstração de alegria com que a aula prosseguia. Não foi observado discente disperso ou conversando sobre algo que não fosse do conteúdo. Todos permaneceram engajados durante a atividade.

Cerca de $98 \%$ dos alunos das disciplinas em que foram desenvolvidas os jogos nunca tiveram aulas iguais a essa. E, cerca de $95 \%$ relataram que gostam de jogos. 
Com relação ao Flash Card Goniométrico, sobre a percepção da facilitação da aprendizagem, $89,6 \%$ alunos consideraram que o conteúdo apresentado em jogo facilitou o aprendizado e $75,8 \%$ dos alunos consideraram que aprenderam o conteúdo com a aula. Considera-se esse resultado importante pois o conteúdo exige grande memorização.

Considerando a motivação, $100 \%$ dos alunos se consideraram motivados com a aula e 93,1\% dos alunos se consideraram motivados a aprofundar o conteúdo apresentado fora do ambiente da sala de aula.

Mesmo não sendo colocado um campo aberto para depoimentos, alguns alunos quiseram se expressar nos espaços em branco da folha da escala deixando sua percepção. Considerou-se importante colocar os relatos pois foram manifestações espontâneas de avaliação da atividade.

"Foi bem interessante e divertido. Precisaríamos de mais tempo para passar por todas as articulações. " (Estudante A)

“(...) gostei bastante da prática.” (Estudante B)

"Estratégia interessante, nos faz lembrar o conteúdo não de uma forma chata, mas tranquila." (Estudante C)

Com relação ao jogo da fratura os alunos conseguiram simular cada um dos traços de fratura encontrados na literatura (FRESENIUS et al., 2007), demonstrando a compreensão do mecanismo biomecânico das forças que atuam na etiologia da lesão. Conforme mostrado na Figura 4. 


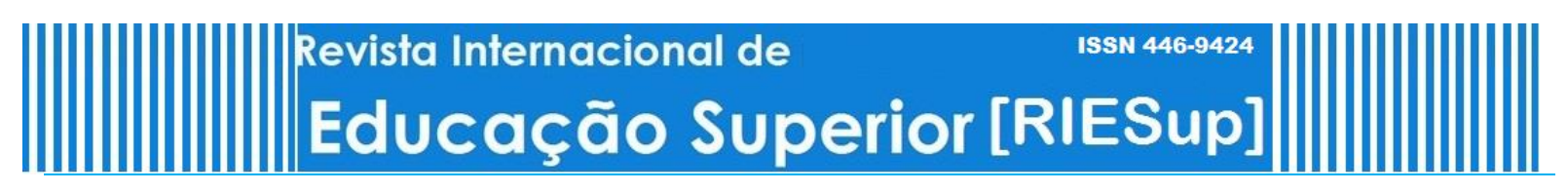

Relato de Experiência

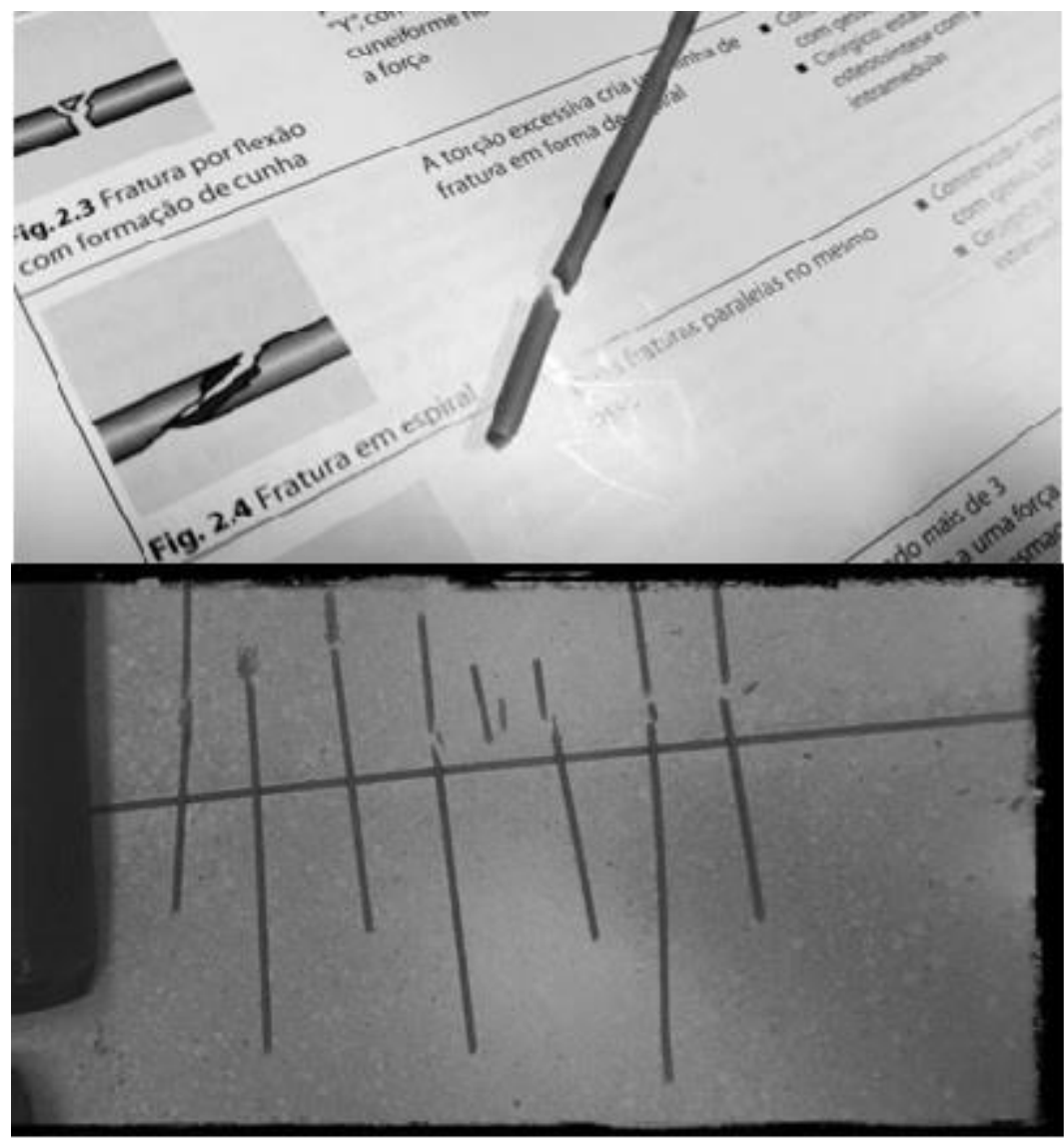

Figura 4. Traços de fratura simulados de acordo com a literatura proposta para a aula Fonte: Fresenius et al. 2007.

Observando as reações durante a aula os alunos se mostraram bem motivados com a atividade. Ao final da atividade foi proposto para os alunos dessa disciplina que realizassem um relatório com as fotos das reproduções das fraturas e exemplos de situações práticas em que os traços poderiam ocorrer. Muitos alunos quiseram também deixar depoimentos, mesmo não tendo sido solicitados a fazê-los. Assim como no jogo do Flash Card, considerou-se importante relatá-los para que se possa ter a percepção do impacto da atividade com os alunos.

“(...) pudemos realizar os diversos tipos de fraturas utilizando o macarrão, que é um recurso diferente e que despertou ainda mais o interesse em participar ativamente da aula." (Estudante D)

“ (...) conseguimos entender a forma com que as fraturas acontecem, entendendo a biomecânica das suas causas e diferenciar os tipos e locais mais comuns em que essas podem acontecer. " (Estudante E) 
Com relação ao jogo da Anatomia Radiológica os alunos se engajaram totalmente na aula e se mostraram completamente interessados.

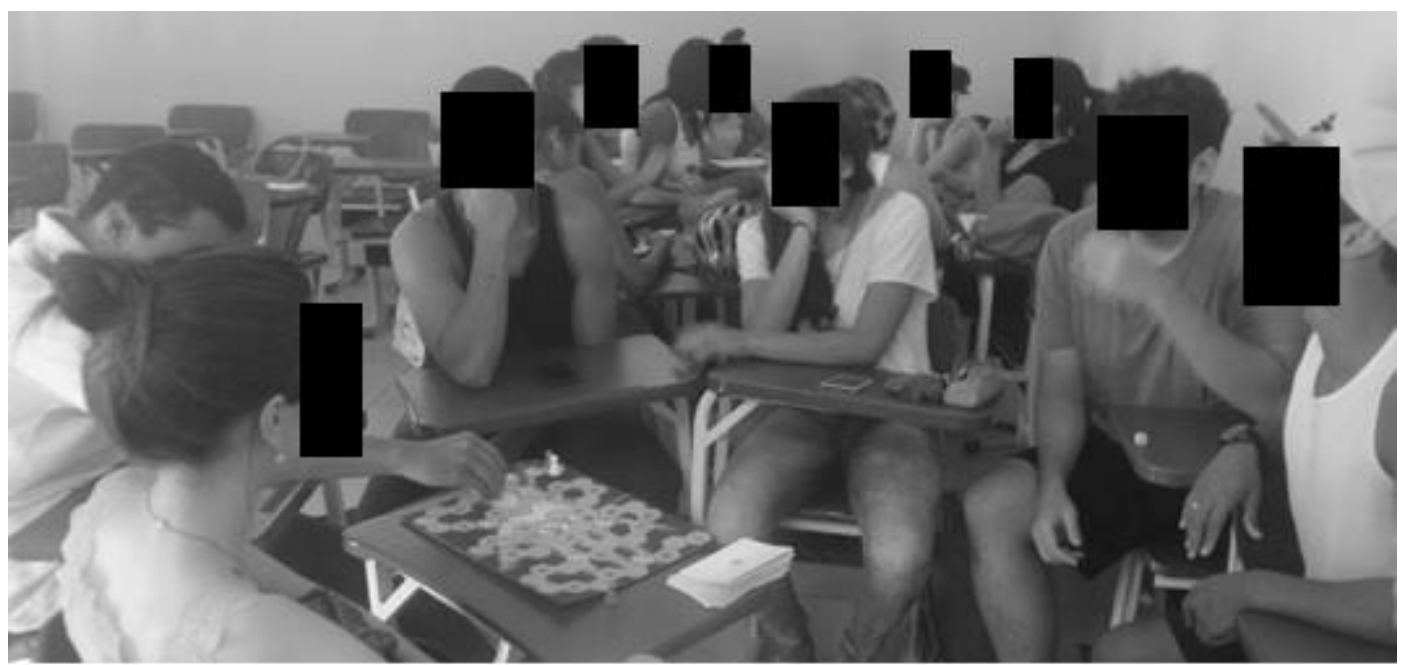

Figura 5. Engajamento dos alunos na proposta de ensino.

Fonte: fotos tiradas pela docente em sala de aula.

Cerca de 85,7 \% alunos consideraram que o conteúdo apresentado em jogo facilitou o aprendizado. Com relação à aprendizagem $85,7 \%$ dos alunos consideraram que aprenderam o conteúdo com a aula. E, 100\% dos alunos se consideraram motivados com a aula. E, 92,8\% dos alunos se consideraram motivados a aprofundar o conteúdo apresentado.

Aqui também não foi solicitado nenhum depoimento além das respostas objetivas da escala, no entanto, alguns alunos quiseram enfatizar sua percepção por meio de um relato escrito conforme descrito a seguir.

“O jogo é muito interessante e instigante." (Estudante F)

"Sua aula é muito 10, professora! A gente sempre sai motivado a aprofundar o assunto (...). Obrigada!"” (Estudante G)

E, $100 \%$ dos alunos consideraram o uso de jogos em sala de aula interessante.

\section{DISCUSSÃ̄0}

Com base nos resultados das três aplicações da gamificação foi interessante observar que nos houve um engajamento dos discentes. A literatura aponta três formas de se verificar o engajamento, uma voltada para o componente comportamental, outra para o emocional e uma última para o cognitivo, mas, dificilmente essas formas estarão dissociadas. O comportamental está relacionado a participação, o envolvimento e as atitudes positivas dos

\begin{tabular}{l|l|l|l|l|l} 
() Rev. Inter. Educ. Sup. & Campinas, SP & v.4 & n.1 & p.221-233 & jan./abr. 2017
\end{tabular}


discentes durante a resolução de atividades. O emocional relaciona-se às reações dos estudantes enquanto cumprem determinada atividade como, por exemplo, o interesse, a alegria, o bem-estar, a tristeza, a ansiedade e a frustração. O cognitivo é marcado pelo esforço para entender o que é estudado e para alcançar níveis mais altos de compreensão (SEIXAS; GOMES; MELO FILHO, 2016).

Foi possível observar e verificar nos depoimentos que em uma análise comportamental os alunos se mostraram participativos, emocionalmente demonstraram interesse, alegria e cognitivamente foi verificado o interesse em alcançar um aprofundamento maior.

Obter os alunos motivados constitui um dos pontos importantes na tarefa do docente. No entanto, essa motivação torna-se aliada do processo de aprendizagem quando é intrínseca, ou seja, quando o desejo de aprender vem do aluno (HANUS; FOX, 2015). Nas três experiências os alunos demonstraram o desejo próprio de aprofundar no conteúdo o que denota que foi atingido a motivação intrínseca dos discentes.

A maioria dos discentes que participaram da experiência afirmaram que gostam de jogos, dessa maneira, considerando que essas novas gerações cresceram em um período em que os jogos estão cada vez mais presentes no cotidiano das pessoas, o uso de jogos em sala de aula foi um ponto atraente e motivador. Além disso, a possibilidade de feedback imediato e frequente que os jogos oferecem, a capacidade de dar aos discentes a liberdade de falhar sem medo de forma que os erros se tornam recuperáveis, torna a atividade ainda mais atrativa (MARTÍ-PARREÑO; SEGUÍ-MAS; SEGUÍ-MAS, 2016). Os alunos enfatizaram tais aspectos em seus depoimentos.

Uma grande dificuldade dentro do ensino em saúde é que algumas situações são difíceis de serem visualizadas no momento em que está acontecendo. A fratura é um dessas dificuldades. Geralmente se vê após o fenômeno ter acontecido por meio da imagem radiológica e, todo o processo causal em termos de forças atuantes, fica no imaginário do discente. Com o jogo da fratura foi possível trazer o invisível aos olhos promovendo uma simulação gamificada de algo que acontece na vida real. Mas o que a literatura aponta é que apenas a simulação sem interação ou que seja apenas demonstrativa sem uma ação do discente, não tem tanto impacto no processo de aprendizagem (PIRKER; GÜTL, 2015). No caso do jogo da fratura, o processo de estar em grupos construindo em conjunto o procedimento da simulação tornou a atividade ativa e mais significativa.

Nas outras experiências também foi utilizada o trabalho em pequenos grupos o que também acionou de certa forma a colaboração que também é um sinal de engajamento (KANTHAN, 2011). Essa colaboração possibilitou uma construção da atividade em grupo estimulando os 
discentes a interagir com os outros em uma maneira ativa construir seus próprios aprendizados.

\section{CONSIDERAÇÕES FINAIS}

Com base no resultado apresentado, o que se pode concluir é que o uso de games em sala de aula pode ser uma estratégia interessante, principalmente para favorecer o aprendizado de conteúdos mais complexos ou de pouco interesse entre os estudantes. O engajamento e a motivação que poderiam estar diminuídos em aulas tradicionais dos conteúdos citados tiveram os seus lugares nas aulas gamificadas descritas no presente trabalho. Assim, essa estratégia cumpriu seu objetivo pedagógico e espera-se que tal experiência possa motivar também docentes não apenas dos cursos de fisioterapia mas de outras áreas a reinventar suas aulas.

\section{REFERÊNCIAS}

AHMED, Maroof et al. Gamification in medical education. Medical Education, n.20, p.1-2, 2015. Disponível em: <https://www.ncbi.nlm.nih.gov/pmc/articles/PMC4590351/> Acesso em: 27 out 2017.

ARAUJO, Eliana Silva Cassimiro; VIEIRA, Vânia Maria Oliveira. Práticas docentes na Saúde: contribuições para uma reflexão a partir de Carl Rogers. Psicologia Escolar e Educacional, n.17, v.1, p. 97-104, 2013. Disponível em: <http://www.redalyc. org/articulo.oa? id=282328025010 >. Acesso em: 27 out 2017

BANFIELD, James; WILKERSON, Brad. Increasing student intrinsic motivation and selfefficacy through gamification pedagogy. Contemporary Issues In Education Research, v. 7, n. 4, p. 291-298, 2014. Disponível em: <https://www.cluteinstitute.com/ojs/index.php/ CIER/article/view/8843/8809 > . Acesso em: 27 out 2017.

FARDO, Luis Marcelo. A gamificação aplicada em ambientes de aprendizagem. Revista Novas Tecnologias em Educação, Porto Alegre, v. 11, n. 1, p.1-9, 2013. Disponível em: < http://www.seer.ufrgs.br/renote/article/view/41629>. Acesso em: 25 out 2017 FRESENIUS, Michael et al. Fisioterapia em traumatologia/cirurgia. São Paulo: Editora Santos, 2007.

HAMARI J.; KOIVISTO J.; SARSA H. Does gamification work?: a literature review of empirical studies on gamification. In: HAWAII INTERNATIONAL CONFERENCE ON SYSTEM SCIENCES, $47^{\text {th }}, 2014$, Haikoloa, HI. [Proceedings of...]. New York: IEEE, 2014. p. 3025-34. 
HANUS, Michael; FOX, Jesse. Assessing the effects of gamification in the classroom: A longitudinal study on intrinsic motivation, social comparison, satisfaction, effort, and academic performance. Computers \& Education, v. 80, p. 152-161, 2015. Disponível em: < http://www.sciencedirect.com/science/article/pii/S0360131514002000 >. Acesso em 25 out 2017.

KANTHAN, G. Strengthening student engagement in the classroom. Singapore: National University of Singapore, 2011.

MARTÍ-PARREÑO, José; SEGUÍ-MAS, Diana; SEGUÍ-MAS, Elies. Teachers' attitude towards and actual use of gamification. Procedia - Social and Behavioral Sciences, v.228, p.682-688, 2016. Disponível em: < http://www.sciencedirect.com/science/article/pii/

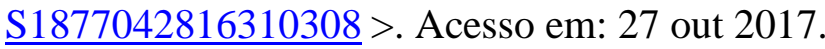

MITRE, Sandra Minardi et al. Metodologias ativas de ensino-aprendizagem na formação profissional em saúde: debates atuais. Ciência \& Saúde Coletiva, São Paulo, v. 13, suppl. 2, p. 2133-2144, 2008. Disponível em: 〈http://www.scielosp.org/scielo.php?pid=S1413-

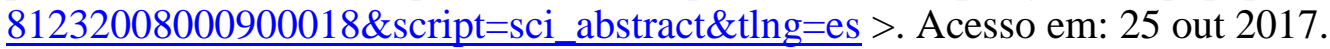

PIRKER, Johanna; GÜTL, Christian. Educational gamified science simulations. In: REINERS, Torsten; WOOD, Lincoln (Ed.). Gamification in Education and Business. [New York]: Springer International Publishing, 2015. p. 253- 275.

ROGERS, Carl. Liberdade de aprender. 2.ed. Porto Alegre: Artes Médicas, 1986

SEIXAS, Luma da Rocha; GOMES, Alex Sandro; MELO FILHO, Ivanildo Jose de. Effectiveness of gamification in the engagement of students. Computers in Human Behavior, v.58, p. 48-63, May 2016. Disponível em: <http://www.sciencedirect.com/science/ article/pii/S0747563215302363> Acesso em 25 out 2017.

\section{Sobre a autora}

Thaís Branquinho Oliveira Fragelli

E-mail: thaisbranquinho@hotmail.com / ORCID: http://orcid.org/0000-0001-9378-0066

Secretaria de Saúde do Distrito Federal - Brasil

Doutorado pelo Ciências da Saúde pela Universidade de Brasília [UnB]. 